\title{
THROMBOTIC MICROANGIOPATHIC HEMOLYTIC ANEMIA IN SYSTEMIC LUPUS ERYTHEMATOSUS IN A 25 YEARS OLD FEMALE IN CHENNAI, INDIA
}

\author{
Manimekalai Periyasamy, (DPon Divya Bharathi, (D) Mullangi Chenchu Vinatha \\ Department of General Medicine, Sree Balaji Medical College and Hospital, Chennai, Tamil Nadu, India
}

\begin{abstract}
Systemic lupus erythematosus (SLE) is an autoimmune condition, affecting multiple organs and tissues by autoantibodies and immune complexes. Hematologic manifestations of SLE include anemia, thrombocytopenia and leukopenia. The most common type of anemia seen in SLE is anemia of chronic disease. Thrombotic microangiopathic hemolytic anemia (TMHA) in SLE is very rare. Incidence of TMHA in children with SLE is common compared to adult cases of SLE. Manifestations of TMHA include presence of schistocytes in the peripheral smear, elevated bilirubin levels, elevated LDH and negative coombs test. This case report focuses on 25-year-old female diagnosed concomitantly with SLE and TMHA, and treated with steroids, blood transfusions, megakaryocyte growth factors and antibiotics.
\end{abstract}

KEY WORDS: Systemic Lupus Erythematosus; Autoantibodies; Anemia; Thrombocytopenia; Leukopenia; Hemolytic Anemia; Microangiopathic Hemolytic Anemia; Hemolytic-Uremic Syndrome; Red Blood Cells; Coombs test.

Cite as: Periyasamy M, Bharathi PD, Vinatha MC. Thrombotic microangiopathic hemolytic anemia in systemic lupus erythematosus in a 25 years old female in Chennai, India [case report]. Gomal J Med Sci 2021 Oct-Dec; 19(4):163-4. https://doi.org/10.46903/gjms/19.04.1050

\section{INTRODUCTION}

Multisystemic manifestation is common in SLE. Common hematological manifestations in SLE are anemia of chronic disease, thrombocytopenia and leukopenia. ${ }^{1}$ Thrombotic microangiopathic hemolytic anemia (TMHA) is a severe type of haemolytic anemia, which includes the presence of schistocytes (fragmented red blood cells) and contracted or distorted red cells in the peripheral smear. Differentials of TMHA are thrombotic thrombocytopenic purpura (TTP), hemolytic-uremic syndrome (HUS), disseminated intravascular coagulopathy (DIC), antiphospholipid antibody syndrome (APLA) and vasculitis. ${ }^{2}$ Treatment for each of these conditions is different and should be identified correctly for proper treatment and response.

\section{CASE REPORT}

A 25-year-old female presented in year 2010 to Shree Balaji Medical College and Hospital, Chennai, India

\section{Corresponding Author:}

Dr. Manimekalai Periyasamy

Associate Professor, Department of General Medicine

Sree Balaji Medical College and Hospital

Chennai, Tamil Nadu, India

E-mail: mekalap32@gmail.com

$\begin{array}{ll}\text { Date Submitted: } & 11-07-2021 \\ \text { Date Revised: } & 23-08-2021 \\ \text { Date Accepted: } & 18-09-2021\end{array}$

with fever, headache, vomiting, generalised joint pain, high coloured urine, melena and skin rashes over the face, hands and legs for two weeks. There was history of bilateral swelling of legs and facial puffiness (on and off), breathlessness, palpitation, hair loss and loss of appetite for one month. On examination patient had severe pallor, angular stomatitis and bilateral pitting pedal edema. Vitals were stable. Investigations showed low hemoglobin $4.2 \mathrm{~g} / \mathrm{dL}$, TLC 21,820 cells/ $\mu \mathrm{L}$, platelet $\langle 10,000$ cells $/ \mu \mathrm{L}$, reticulocyte index 2.9 , altered liver function tests (elevated bilirubin levels and liver enzymes) and raised LDH $1555 \mathrm{U} / \mathrm{L}$. Peripheral smear showed schistocytes and markedly reduced platelet count. Coombs test was negative. ANA was positive (speckled pattern+). DNA Ab, $\mathrm{Ku}, \mathrm{Sm}$, Histones and Sm/RNP were positive. APLA and RF were negative. Complement levels were decreased; C3 42.46 (normal $90-180 \mathrm{mg} / \mathrm{dL}$ ) and C4 1.26 (normal $10-40 \mathrm{mg} / \mathrm{dL}$ ), which reverted back to the normal range. Urine routine showed $1+$ proteins and urine PCR was $<0.5 \mathrm{~g}$. Ultrasound abdomen was normal. Blood culture showed growth of MRSA.

Diagnosis of SLE concomitant with TMHA was made. Patient was started on injection methyl prednisolone $500 \mathrm{mg}$ (pulse therapy) and injection hydroxychloroquine $200 \mathrm{mg}$. Platelet and packed red blood cell transfusions were done. Oral megakaryocyte growth factor eltrombopag $50 \mathrm{mg}$ was started as twice daily dose. Haemoglobin improved to $9.5 \mathrm{~g} / \mathrm{dL}$ and 
platelets improved to 119,000 cells $/ \mu \mathrm{L}$.

Patient was symptomatically better and during discharge patient was advised to continue Tablets prednisolone $40 \mathrm{mg}$ once daily, hydroxychloroquine $200 \mathrm{mg}$ once daily and Mycophenolate mofetil (MMF) $500 \mathrm{mg}$ twice daily and was followed up regularly every month. So far in June 2021, she did not have any symptoms or flare with the same medications.

\section{DISCUSSION}

SLE can present with different hematological manifestations. A very rare but serious form of anemia in SLE is TMHA. ${ }^{3}$ Pathogenesis of TMHA involves the fragmentation of the red blood cells due to the shearing stress from the arterial blood flow in abnormal microcirculation. In TMHA, there is increased activation of the coagulation cascade by circulating immune complexes, causing fibrin deposition and endothelial cell proliferation. These further causes immune mediated endothelial damage and red blood cell fragmentation. TMHA with features of thrombotic thrombocytopenic purpura (TTP) or hemolytic uremic syndrome (HUS) is uncommon but should be ruled out for prompt treatment. Pentads of thrombotic microangiopathies (TMA) include thrombocytopenia, microangiopathic hemolytic anemia, fever, renal involvement and neurological symptoms. HUS is triad of renal failure, thrombocytopenia and microangiopathic hemolytic anemia. ${ }^{4} \mathrm{~A}$ combination of both TTP and HUS is known as thrombotic microangiopathic hemolytic anemia (TMHA). TTP and TMHA should be treated with plasmapheresis along with steroids sequentially to decrease the mortality. ${ }^{5}$ Decreased levels of complement factors in a case of active SLE and TMHA might also suggest associated vasculitis. Antiphospholipid antibody syndrome can also present in similar scenario, hence should be ruled out.

\section{CONCLUSION}

Any SLE patient presenting with fever, hemolytic anemia, thrombocytopenia with neurological symptoms or renal failure; diagnosis of thrombotic microangiopathic hemolytic anemia (TMHA) should be considered. TMHA can present concomitantly with or preceding SLE symptoms. TMHA should be differentiated from SLE exacerbation in a known case of SLE. Early diagnosis and prompt treatment with plasmapheresis and steroids is important in order to decrease the mortality rate.

\section{REFERENCES}

1. Kokori SI, loannidis JP, Voulgarelis M, Tzioufas AG, Moutsopoulos HM. Autoimmune hemolytic anemia in patients with systemic lupus erythematosus. Am J Med 2000;108:198-204. https://doi.org/10.1016/ S0002-9343(99)00413-1

2. Brain MC, Dacie JV, Hourihane DO. Microangiopathic haemolytic anaemia: the possible role of vascular lesions in pathogenesis. Br J Haematol 1962;8:358-74. https://doi. org/10.1111/j.1365-2141.1962.tb06541.x

3. Brunner HI, Freedman M, Silverman ED. Close relationship between systemic lupus erythematosus and thrombotic thrombocytopenic purpura in childhood. Arthritis Rheum 1999;42:2346-55. https://doi. org/10.1002/1529-0131(199911)42:11<2346::AIDANR13>3.0.CO;2-X

4. Ridolfi RL, Bell WR. Thrombotic thrombocytopenic purpura: report of 25 cases and review of the literature. Medicine (Baltimore) 1981;60:413-28. https:// doi.org/10.1097/00005792-198111000-00003

5. Lewis EJ, Hunsicker LG, Lan SP, Rohde RD, Lachin JM, and the Lupus Nephritis Collaborative Study Group. A controlled trial of plasmapheresis therapy in severe lupus nephritis. $\mathrm{N}$ Eng $\mathrm{J}$ Med 1992;326:1373-9. https://doi.org/10.1056/ NEJM199205213262101

\section{CONFLICT OF INTEREST \\ Authors declare no conflict of interest. \\ GRANT SUPPORT AND FINANCIAL DISCLOSURE None declared.}

\section{AUTHORS' CONTRIBUTION}

The following authors have made substantial contributions to the manuscript as under:

Conception or Design:

Acquisition, Analysis or Interpretation of Data:

Manuscript Writing \& Approval:
MP
MP, PDB, MCV
MP, PDB, MCV

All the authors agree to be accountable for all aspects of the work in ensuring that questions related to the accuracy or integrity of any part of the work are appropriately investigated and resolved.

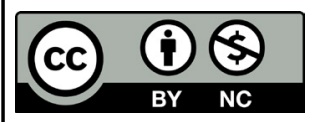

Copyright (C) 2021. Manimekalai Periyasamy, et al. This is an Open Access article distributed under the terms of the Creative Commons Attribution-NonCommercial 4.0 International License, which permits unrestricted use, distribution \& reproduction in any medium provided that original work is cited properly. 